(c) (i)

\title{
Kentsel yeşil alanların kalitesinin insan sağlığı ve fiziksel aktivitesi üzerindeki etkisinin incelenmesi
}

\author{
Assessing effects of the quality of urban green spaces on people's health and physical activity
}

\author{
Abdullah AKPINAR \\ Aydın Adnan Menderes Üniversitesi Ziraat Fakültesi Peyzaj Mimarlığı Bölümü Aydın, Türkiye
}

\section{Eser Bilgisi/Article Info}

Araştırma makalesi / Research article

DOI: $10.17474 /$ artvinofd. 447220

Sorumlu yazar/Corresponding author

Abdullah AKPINAR

e-mail: aakpinar@adu.edu.tr

Geliş tarihi / Received

24.07.2018

Düzeltme tarihi / Received in revised form

12.02.2019

Elektronik erişim / Online available

12.02.2019

Anahtar kelimeler:

Kentsel yeşil alanlar

Fiziksel aktivite

Yeşil alan kalitesi

Stres

Ruh ve beden sağlığı

Keywords:

Urban green spaces

Physical activity

Green space quality

Stress

Mental and physical health

\begin{abstract}
Özet
Kentlerde yaşam kalitesinin önemli bir göstergesi olarak kabul edilen kentsel yeşil alanların önemi şehirleşmeyle birlikte her geçen gün artmaktadır. Bu sebeple, bu çalışmanın amacı kentsel yeşil alanların kalitesi ile insanların fiziksel aktivite düzeyleri ve sağlıkları arasındaki ilişkiyi belirlemektir. Bu çalışmanın verileri, Aydın kent merkezinde bulunan yedi farkı kentsel yeşil alanda, 1 Nisan-15 Mayıs 2016 tarihlerinde kentsel yeşil alanları fiziksel aktivite için aktif olarak kullanan 394 kullanıcıyla yüz yüze bireysel görüşmeler yapılarak toplanmıştır. Katılımcıların sosyo-ekonomik durumları istatistiki olarak kontrol edilerek çoklu regresyon analiz yöntemi ile kentsel yeşil alanların kalitesi ile insanların fiziksel aktivite düzeyleri ve stres seviyeleri, ruh ve beden sağlıkları arasındaki ilişki incelenmiştir. Çoklu regresyon analizi sonucunda insanların fiziksel aktiviteleri ile yeşil alanların eve yakınlığı arasında pozitif anlamlı bir ilişki bulunmuştur. Diğer taraftan, insanların fiziksel aktiviteleri ile yeşil alanların bakımlı ve temiz olması arasında pozitif anlamlı ilişki tespit edilmiştir. Yeşil alanların büyüklüğü ve temizliğinin ise daha az stres ile, yeşil alanların açık ve görünür olmasının da daha iyi fiziksel sağlıkla pozitif anlamlı ilişkili olduğu bulunmuştur. Ayrıca fiziksel aktivite süresinin daha iyi fiziksel sağlık ile pozitif anlamlı ilişkili olduğu belirlenmiştir. Bu araştırmanın sonuçları yeşil alanların insanların fiziksel aktiviteleri ve sağııkları açısından evlerine yakın mesafelerde olması gerektiğini önermektedir. Belirli kalitedeki kentsel yeşil alanların insanların fiziksel olarak daha aktif, ruh ve beden sağlığı açısından da daha sağlıklı olmalarına katkı yapacağını göstermektedir.
\end{abstract}

\begin{abstract}
The importance of urban green spaces, which is accepted as an important indicator of the quality of life in cities, is increasing day by day along with urbanization. Therefore, the purpose of this study was to determine the relationship between the quality of urban green spaces and people's physical activity levels and health. The data of this study were collected in face-to-face interviews with 394 users who actively use urban green spaces for physical activity on April 1 to May 15, 2016 in seven different urban green spaces in Aydın city center. While the socio-economic status of participants was statistically controlled, the relationships between the quality of urban green spaces and people's physical activity levels, stress levels, mental and physical health were examined. In the regression analysis, a positive relationship between people's physical activity levels and close distance to urban green space from home was found. On the other hand, there were positive relationships between people's physical activities and the maintenance and cleanliness of the urban green spaces. Whereas positive relationships were found between largeness and cleanliness of urban green spaces and less stress. In addition, a positive relationship was found between open and visible urban green spaces and better physical health. It was also found that the duration of physical activity was positively related to better physical health. The results of this study suggest that urban green spaces should be close to people's homes in terms of their physical activities and health. Certain quality of urban green spaces would help people to be more physically active and healthier in terms of mental and physical health.
\end{abstract}

\section{Giriş}

Bugün, fiziksel hareketsizlik Dünya Sağlık Örgütü tarafından küresel çapta gerçekleşen doğal ölümlere neden olan, dördüncü önde gelen risk faktörü olarak tanımlanan önemli bir konu haline gelmiştir (WHO 2019). Araştırmalar, fiziksel hareketsizliğin kronik hastalıklar, meme ve kolon kanserleri, diyabet, koroner kalp hastalığı, psikolojik bozukluklar ve şişmanlık gibi ciddi sağlık sorunlarına yol açan temel faktör olduğunu ve yaşam beklentisini kısalttığını ortaya koymaktadır (Lee ve ark. 2012; Sallis ve ark. 2012; The Ministry of Health 2014). 2012 yılı itibariyle dünya genelinde yetişkinlerin \%31.1 fiziksel olarak hareketsizdir (Hallal ve ark. 2012) ve ülkemizde bu oran kadınlar için \%76.5 iken, erkekler için \%67.50’dir (Sağlık Bakanlığı 2014). 
Fiziksel hareketsizliğin negatif etkileri göz önünde bulundurulduğunda, insanların fiziksel aktivite düzeylerini artırmak önemli bir hal almaktadır. Bunu yapabilmek için fiziksel aktivite ile ilgili faktörleri bilmek ve anlamak önemlidir (Schipperijn ve ark. 2013; Koohsari ve ark. 2015). Bu bağlamda halk sağlığı ile ilgili araştırma yapan bilim insanları tarafından sosyo-ekolojik modeller fiziksel aktivite düzeyini belirleyici sebepleri anlamak için sıkça kullanılmaktadır (Sallis ve ark. 2006; Sallis ve ark. 2008). Bu modelde mamur çevre (built environment) insanların fiziksel aktivite düzeylerini artırıcı ya da azaltıcı etkiye sahip en önemli faktörlerden biri olarak kabul edilmektedir (Sallis ve ark. 2008 ve 2012). Parklar ya da yeşil yollar gibi kentsel yeşil alanlar insanlar tarafından yapılandırılmış çevre içerisinde insanlara fiziksel aktivite imkânı sunan önemli alanlar olarak kabul edilmektedir (Bedimo-Rung ve ark. 2005; Kaczynski ve Henderson 2007; Koohsari ve ark. 2015 Dadvand ve ark. 2016).

Bu kapsamda yapılan bilimsel araştırmalar kentsel yeşil alanların fiziksel aktivite düzeyi ile ilişkili olduğunu ortaya koymaktadır (Cohen ve ark. 2007; Sugiyama ve ark. 2008; Kaczynski ve ark. 2009; Amorim ve ark. 2010; Schipperijn ve ark. 2013, Hartig ve ark. 2014). Araştırmalar kentsel yeşil alana olan yakın mesafenin insanların fiziksel aktivite düzeyleri (Foster ve ark. 2004; Giles-Corti ve ark. 2005; Cohen ve ark. 2007; Kaczynski ve ark. 2009; Toftager ve ark. 2011; Akpınar 2016a; Akpınar ve Cankurt 2017) ve kentsel yeşil alanı kullanma sıklıklarıyla (Cohen ve ark. 2007; Mowen ve ark. 2007; Schipperijn ve ark. 2010; Akpınar 2014) pozitif olarak ilişkili olduğunu göstermektedir. Çalışmalar ayrıca döşemeli yürüyüş yolları (Kaczynski ve ark. 2008; Reed ve ark. 2008), spor alanları (Cohen ve ark. 2006; Floyd ve ark. 2008), su öğeleri (Kaczynski ve ark. 2008; Schipperijn ve ark. 2013), çocuk oyun alanları (Cohen ve ark. 2006; Kaczynski ve ark. 2008), çok sayıda ağaç (Kaczynski ve ark. 2008; Schipperijn ve ark. 2013), ışıklandırma ve yürüyüş patikaları (Cohen ve ark. 2006; Schipperijn ve ark. 2013; Akpınar 2016b), araç ve bisiklet park alanları (Schipperijn ve ark. 2013) ve içme suyu ve gölgelik mekanlar (Cohen ve ark. 2006; Akpınar 2016b) gibi belirli karakteristik özelliklere sahip kentsel yeşil alanların fiziksel aktivite düzeyi ile ilişkili olduğunu ortaya koymuştur.
Ayrıca yapılan araştırmalar kentsel yeşil alanların kalitesinin de insan fiziksel aktivite düzeyi üzerinde olumlu etkiye sahip olduğunu göstermektedir. Örneğin, estetik (Ball ve ark. 2001; Giles-Corti ve ark. 2005; Evenson ve arkç 2006; McCormack ve ark. 2010; Sugiyama ve ark. 2010), bakımlı (McCormack ve ark. 2010; Akpınar 2016a) ve temiz (Duncan ve Mummery 2005; McCormack ve ark. 2010; Akpınar 2016a) kentsel yeşil alanlar fiziksel aktivite düzeyini pozitif olarak etkilemektedir. Çalışmalar aynı zamanda kentsel yeşil alan kalitesinin insanların esenlik hissi (Bowler ve ark. 2010), genel sağlığı (de Jong ve ark. 2011; Francis ve ark. 2012; de Vries ve ark. 2013; Paquet ve ark. 2013) ve ruh sağlığı (de Vries ve ark. 2013) ile ilişkili olduğunu ortaya koymuştur. Diğer taraftan bazı araştırmaların sonucunda kentsel yeşil alan ile fiziksel aktivite ve sağlık arasında herhangi bir ilişki bulamamıştır (Hillsdon ve ark. 2006; Taylor ve ark. 2008; Maas ve ark. 2008; McCormack ve ark. 2008; Jones ve ark. 2009; Sugiyama ve ark. 2013; de Vries ve ark. 2013). Yine bu konu ile ilgili yapılan derleme çalışmaları da farklı sonuçlar göstermektedir (Kaczynski ve Henderson 2007; McCormack ve ark. 2010; Lachowycz ve Jones 2011; Koohsari ve ark. 2015; Bancroft ve ark. 2015). Örneğin Lachowycz ve Jones (2011)'un yaptıkları çalışmada, 2000-2010 yılları arasında yapılan çalışmaların sadece $\% 40$ 'ının yeşil alanlar ve fiziksel aktivite düzeyi ile ilişkili olduğu saptanmıştır.

Ortaya çıkan bu farklı sonuçlar özellikle yerel yöneticiler, şehir bölge plancıları ve peyzaj mimarlarının aklını karıştırmakta ve sağlıklı kararlar vermelerini engellemektedir (Koohsari ve ark. 2015; Akpınar 2016a). Öyle ki, yeşil alanlar ve fiziksel aktivite arasındaki ilişkinin daha fazla araştırılması gerektiği önerilmektedir (Koohsari ve ark. 2015; Akpınar 2016a ve 2016b). Buna ek olarak, kentsel yeşil alanların insan sağlığına etkisinin yeşil alanların kalitesine bağlı olduğu (Paquet ve ark. 2013; Akpınar 2016a) ve bu sebepten ötürü yeşil alan kalitesinin insan fiziksel aktivite üzerindeki etkisinin de araştırılması gerektiği de araştırmalarda vurgulanmıştır (McCormack ve ark. 2010). Ayrıca, bu konu hakkında ülkemizde yapılan araştırmalar oldukça yenidir (Akpınar 2014, 2016a ve 2016b) ve daha fazla araştırmaya ihtiyaç duyulmaktadır. Bu doğrultuda bu çalışmanın amacı kentsel yeşil alanların kalitesi ile insanların fiziksel 
aktivite düzeyleri ve sağılıkları arasındaki ilişkiyi araştırmaktır. Bu çalışmada şu soruların cevapları aranmıştır: 1) Kentsel yeşil alanların kalitesi ile insanların fiziksel aktivite sıklığı ve süreleri arasındaki ilişki nedir? 2) Kentsel yeşil alanların kalitesi ile insanların stres, ruh ve beden sağlıkları arasındaki ilişki nedir?

\section{MATERYAL VE YÖNTEM}

Bu çalışmanın ana materyalini Aydın şehir merkezindeki parkları ve yeşilyolları aktif olarak kullanan kullanıcılar oluşturmaktadır. Kullanılan yöntem ise kullanıcılarla yapılmış olan anket çalışması ile yapılan nicel analiz oluşturmuştur. Materyal ve yöntem hakkında detaylı bilgi aşağıda verilmiştir.

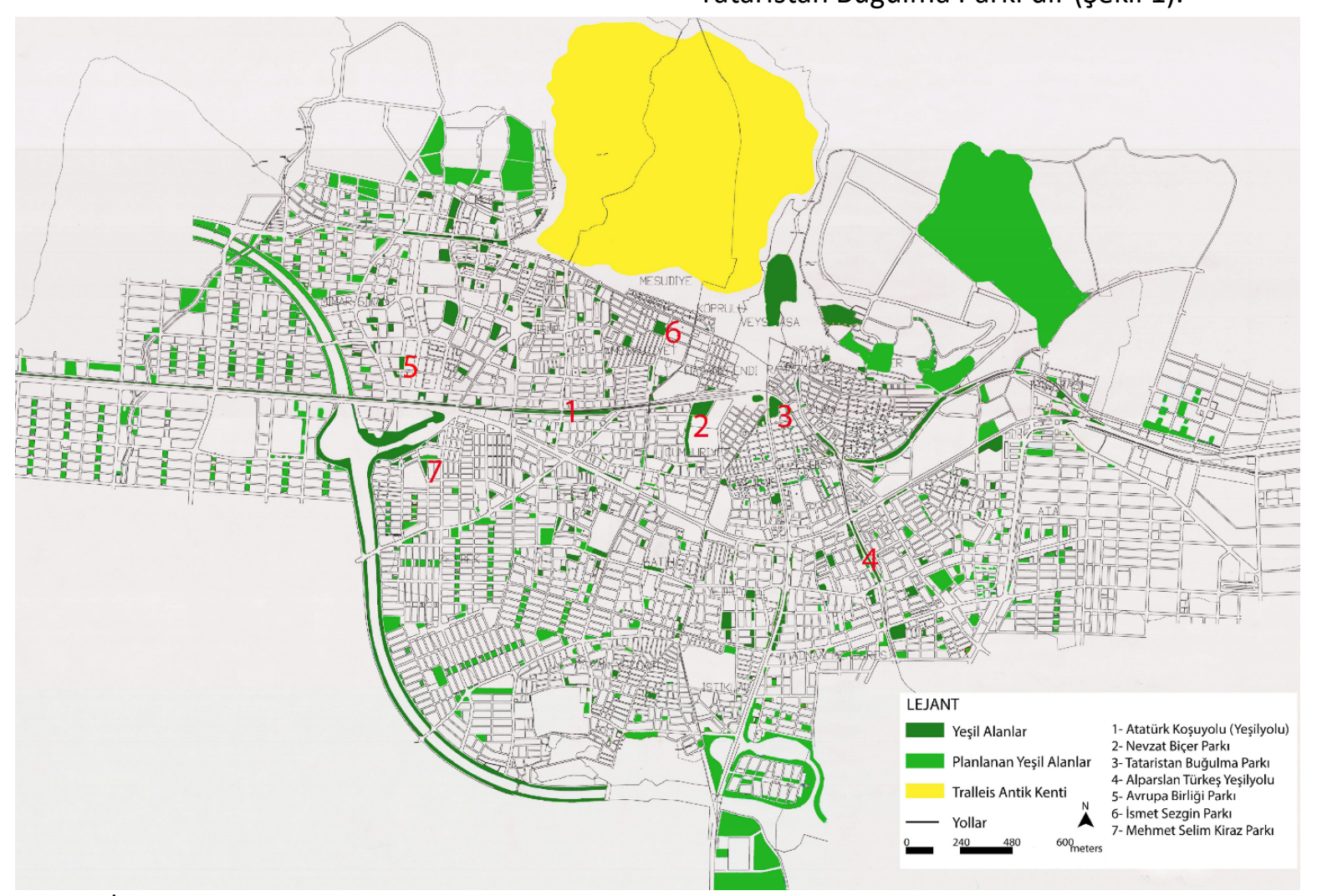

Şekil 1. Çalışma alanı (İmar ve Şehircilik Dairesi Başkanlığı, 2013)

\section{Verilerin Elde Edilmesi}

Bu çalışmada veriler alanda kullanıcılarla yüz yüze yapılan anket çalışmasıyla kişisel bildirim (self-report) yöntemi kullanılarak toplanmıştır. Bu ankette belirlenen kentsel yeşil alanları aktif olarak kullanan kullanıcılarla yapılan anket dört kısımdan oluşmaktadır. Verilerin toplanmasında kullanılan parametreler daha önce

\section{Çalışma Alanı}

$\mathrm{Bu}$ araştırma için seçilen kentsel yeşil alanlar Efeler Belediyesi (Aydın) sınırları içeresinde yer alan 7 farklı yeşil alan olmuştur. Aydın kent merkezinde parkların genelde küçük ve dağınık olması sebebiyle öncelikle insanların fiziksel aktivite yapabilecekleri büyük ve kullanıcı sayısının fazla olduğu parklar belirlenmiştir. Farklı sosyal, kültürel ve ekonomik düzeydeki insanlara erişebilmek için, mahalle bazında veri olmaması sebebiyle, ilk olarak belirlenen 22 kentsel yeşil alan içerisinde mahalle muhtarları ile görüşülerek farklı mahallelerde insanların yoğun olarak kullandıkları 7 kentsel yeşil alan belirlenmiştir. Belirlenen bu alanlar Atatürk Koşuyolu (Yeşilyol), Alparslan Türkeş Yürüyüş Yolu (Yeşilyol), Avrupa Birliği Parkı, İsmet Sezgin Parkı, Mehmet Selim Kiraz Parkı, Nevzat Biçer Parkı ve Tataristan Buğulma Parkı'dır (Şekil 1). kullanıcı tercihlerini belirleyen yurt içi ve yurt dışında yapılmış örnek çalışmalardan yararlanılarak hazırlanmıştır (Schipperijn ve ark. 2013; Peschardt ve Stigsdotter 2013; Akpınar 2016a). Birinci kısımda katılımcılara demografik özellikleri (cinsiyet, yaş, medeni hali, eğitim seviyesi, iş durumu ve aylık geliri) sorulmuştur. İkinci kısımda, kentsel yeşil alanların 
katılımcıların evlerine olan uzaklığı, kentsel yeşil alanları fiziksel aktivite için kullanım sıklıkları, kentsel yeşil alanlarda harcadıkları zaman Likert tipi skorlama ile (1=Hiçbir zaman/Nadiren-5=Her gün; 1=15 dak az-5=2 saatten fazla) toplanmıştır. Üçüncü kısımda ise, bir park, yürüyüş yolu, rekreasyon alanı vb. yeşil alanlarda yürüyüş, egzersiz ya da spor yapmak amacıyla fiziksel aktivitede bulanmalarında yeşil alanların kalitesinin (estetik, temizlik, büyüklük, vb.) etkisi Likert tipi skorlama ile (1=Çok az-5=Çok fazla) toplanmıştır. Son olarak katılımcıların stres, ruh sağlığı ve genel sağlık durumları "son iki haftanızı düşünerek stres, ruh sağlığı ve genel sağlığınızı nasıl değerlendirirsiniz?" sorusuyla kişisel bildirim yöntemi kullanılarak Likert tipi skorlama ile toplanmıştır.

Veriler 1 Nisan-15 Mayıs 2016 tarihleri arasında hafta içi ve hafta sonu olmak üzere hava şartlarının elverdiği nispette, genelde güneşli ve aydınlık günlerde her gün sabah (07:00-09:00), öğlen (12:00-14:00) ve ikindi-akşam vakitlerinde (17:00-20:00) toplanmıştır. Yapılan bu çalışmanın yeterli, güvenli ve temsil edilebilir olabilmesi için örneklem büyüklüğü belirlenmiştir. Bu belirlemede de şu formül kullanılmıştır:

Gerekli Kişi Sayısı=(Z-skor) ${ }^{2}$-Standart Sapma*(1-Standart Sapma)/(yanılma payı) ${ }^{2}$.

Burada Z-skor güven seviyesi \%95'e denk gelen 1.96 alınmıştır, standart sapma 0.5 olup hata payı $\% 5$ kabul edilmiştir (Smith 2013). Bu şartlarda gerekli olan en az kişi sayısı 385 kişi olarak tespit edilmiştir. Bu doğrultuda belirlenen kentsel yeşil alanları aktif olarak kullanan 18 yaş ve üzeri yetişkin kişilerle gönüllülük esasına dayanarak anket çalışması yapılmıştır. Bu kapsamda 420 kişiye yüz yüze anket yapılma talebi iletilmiş ve bu kişilerden 26 kişi anket yapılması teklifine olumsuz cevap vermiştir. Katılımcılar anket yapılmadan önce anket içeriği ile ilgili bilgilendirilmiş ve anket sırasında katılımcıların istedikleri zaman anketi sonlandırabilecekleri söylenmiştir. Toplamda 394 kişi anketi tamamlamıştır ve sonuç olarak gerekli olan 385 sayısına ulaşıldığı için veri toplama işlemi tamamlanmıştır.

\section{Verilerin Analizi}

Verilerin toplanmasında sonra tasnif edilmesi ve bilgisayar ortamına aktarılması işlemine geçilmiştir. Verilerin değerlendirilmesi için SPSS (Statistical Package for Social Sciences) 24.0 paket programından yararlanılmıştır. Veriler bilgisayara aktarılmadan önce istatistiksel hesaplamada kolaylık sağlaması amacıyla kodlanmıştır. Kentsel yeşil alanların kalitesi ile insanların fiziksel aktivite düzeyleri ve sağlıkları arasındaki ilişkinin belirlenmesinde genel istatistiksel karakteristikleri için açıklayıcı tanımsal istatistiksel hesaplamalar yapılmıştır. Ayrıca toplanan verilerin normal dağılıp dağılmadıkları Kolmogorov-Smirnov test çarpıklık testi ile kontrol edilmiştir. Daha sonra değişkenler arasında Çoklu Doğrusallık Sorunu (Multicollinearity Issue) kontrol edilmiştir. Sonraki aşamada ise kentsel yeşil alanların kalitesi ile yetişkinlerin fiziksel aktivite düzeyleri ve stres seviyeleri, ruh ve beden sağlıkları arasındaki ilişki çoklu regresyon analizi kullanılarak analiz edilmiştir. İstatistiksel anlamlılık düzeyi olarak $p \leq .05$ kullanılmıştır.

\section{BULGULAR}

\section{Kullanıcı Karakteristikleri ve Tanımsal İstatistikler}

Çizelge 1 'de görüldüğü üzere cinsiyet açısından katılımcılar eşite yakın bir orandadır (\%49.7'si erkek ve \%50.3'ü kadın). 25-34 yaş grubu en yüksek katılımın sağlandığı yaş grubu olup, evli katılımcı sayısı en fazladır (\%52.3). Eğitim seviyesi açısında en yüksek katııımı \%44.4 ile üniversite ( 2 yıllık ya da 4 yıllık fakülte) mezunları oluşturmuştur. Katılımcıların \%46.2'sini çalışan kişiler oluşturmuştur. Aylık gelir açısından ise en yüksek katılım \%39.3 ile 1000 ila 1999 arası aylık gelire sahip kişiler olmuştur.

Çizelge 2'de görüldüğü gibi katılımcıların \%36.3 ile az stresli olduğu ve ruh sağlığı açısından ise \%40.9 ile iyi seviyesinde olduğunu belirtmiştir. Katılımcıların genel sağlık seviyeleri ise \%46.7 ile iyi seviyesinde olduğunu görülmüştür. Katılımcıların fiziksel aktivite sıklıklarına ve sürelerine bakıldığında, en yüksek fiziksel aktivite sıklığı seviyenin \%32.2 ile haftada birkaç kere olduğu; en yüksek harcanan sürenin ise \%37.6 ile 1-2 saat arası olduğu tespit edilmiştir. 
Çizelge 1. Araştırmaya katılan kullanıcıların karakteristik özellikleri

\begin{tabular}{|c|c|c|c|}
\hline Faktörler & & Frekans & Yüzde \\
\hline \multirow{2}{*}{ Cinsiyet } & Erkek: & 196 & $\% 49.7$ \\
\hline & Kadın: & 198 & $\% 50.3$ \\
\hline \multirow[t]{6}{*}{ Yaş } & 18 - 24 yaş grubu: & 96 & $\% 24.4$ \\
\hline & 25 - 34 yaş grubu: & 110 & $\% 27.4$ \\
\hline & $35-44$ yaş grubu: & 75 & $\% 19$ \\
\hline & 45 - 54 yaş grubu: & 65 & $\% 16.5$ \\
\hline & 55 - 64 yaş grubu: & 37 & $\% 9.4$ \\
\hline & 65 - 71 yaş grubu: & 13 & $\% 3.3$ \\
\hline \multirow{3}{*}{ Medeni Hal } & Bekâr: & 167 & $\% 42.4$ \\
\hline & Evli: & 206 & $\% 52.3$ \\
\hline & Diğer (Boşanmış ya da Dul): & 21 & $\% 5.3$ \\
\hline \multirow[t]{5}{*}{ Eğitim Durumu } & ilkokul ya da altı: & 44 & $\% 11.2$ \\
\hline & Ortaokul: & 35 & $\% 8.9$ \\
\hline & Lise: & 117 & $\% 29.7$ \\
\hline & Üniversite (2 ya da 4 yıllık): & 175 & $\% 44.4$ \\
\hline & Yüksek Lisans/Doktora: & 23 & $\% 5.8$ \\
\hline \multirow[t]{4}{*}{ İş Durumu } & Çalışıyor: & 182 & $\% 46.2$ \\
\hline & Çalışmıyor: & 98 & $\% 24.9$ \\
\hline & Emekli: & 43 & $\% 10.9$ \\
\hline & Öğrenci: & 71 & $\% 18$ \\
\hline \multirow[t]{7}{*}{ Aylık Gelir } & €999 ve az: & 45 & $\% 11.4$ \\
\hline & 1000-1999 arası: & 155 & $\% 39.3$ \\
\hline & 2000-2999 arası: & 98 & $\% 24.9$ \\
\hline & 3000-3999 arası: & 56 & $\% 14.2$ \\
\hline & 4000-4999 arası: & 26 & $\% 6.6$ \\
\hline & 5000-4999 arası: & 5 & $\% 1.3$ \\
\hline & $>6000:$ & 9 & $\% 2.3$ \\
\hline
\end{tabular}

Çizelge 2.Katılımcıların sağlık durumları ve fiziksel aktivite sıklıkları ve süreleri

\begin{tabular}{|c|c|c|c|}
\hline Faktörler & & Frekans & Yüzde \\
\hline \multirow[t]{5}{*}{ Stres } & Çok fazla: & 36 & $\% 9.9$ \\
\hline & Fazla: & 55 & $\% 14$ \\
\hline & Normal: & 117 & $\% 29.7$ \\
\hline & $A z:$ & 143 & $\% 36.3$ \\
\hline & Çok az: & 40 & $\% 10.1$ \\
\hline \multirow[t]{5}{*}{ Ruh Sağlığı } & Çok kötü: & 18 & $\% 4.6$ \\
\hline & Kötü: & 40 & $\% 10.2$ \\
\hline & Normal: & 123 & $\% 31.2$ \\
\hline & İyi: & 161 & $\% 40.9$ \\
\hline & Çok iyi: & 52 & \%13.2 \\
\hline \multirow[t]{5}{*}{ Genel Sağlık } & Çok kötü: & 7 & $\% 1.8$ \\
\hline & Kötü: & 23 & $\% 5.8$ \\
\hline & Normal: & 83 & $\% 21.1$ \\
\hline & İyi: & 184 & $\% 46.7$ \\
\hline & Çok iyi: & 97 & $\% 24.6$ \\
\hline \multirow[t]{5}{*}{ Fiziksel Aktivite Sıklığı } & Hiçbir zaman/nadiren: & 49 & $\% 12.4$ \\
\hline & Ayda birkaç kere: & 67 & $\% 17$ \\
\hline & Haftada bir: & 101 & $\% 25.6$ \\
\hline & Haftada birkaç kere: & 127 & $\% 32.2$ \\
\hline & Her gün: & 50 & $\% 12.7$ \\
\hline \multirow[t]{5}{*}{ Fiziksel Aktivite Süresi } & $15 \mathrm{dk} . \mathrm{az}:$ & 28 & \%7.1 \\
\hline & $15-30 \mathrm{dk} .:$ & 54 & $\% 13.7$ \\
\hline & 30dk.-1 saat: & 126 & $\% 32$ \\
\hline & 1-2 saat: & 148 & $\% 37.6$ \\
\hline & 2 saatten fazla: & 38 & \%9.6 \\
\hline
\end{tabular}

Kentsel Yeşil Alanların Kalitesi ile Yetişkinlerin Fiziksel Aktivite Düzeyleri, Stres Seviyeleri ve Ruh ve Beden Sağııkları Arasındaki îlişki

Doğrusal regresyon istatistiksel analizi ile kentsel yeşil alanların kalitesi ile yetişkinlerin fiziksel aktivite düzeyleri, stres seviyeleri ve ruh ve beden sağlıkları arasındaki ilişki incelenmiştir. Çizelge 3'de görüldüğü gibi eşdeğişken faktörler kontrol edildikten sonra regresyon analizi göstermiştir ki, yeşil alanlara olan mesafe ile insanların fiziksel aktivite sıklıkları arasında negatif anlamlı bir ilişki vardır ( $b=-0.136, \mathrm{SE}=0.031, \% 95 \mathrm{Cl}=-$ 0.237--0.036), yani yeşil alanlara olan mesafe kısaldıkça insanların fiziksel aktiviteye gitme sıklıkları artmaktadır. Regresyon analizi ayrıca göstermiştir ki, temiz $(b=0.380$, $\mathrm{SE}=0.182,95 \% \mathrm{Cl}=0.022-0.739)$ ve bakımlı $(b=0.329$, $\mathrm{SE}=0.162,95 \% \mathrm{Cl}=0.011-0.648$ ) yeşil alanlar ile insanların fiziksel aktivite sıklıkları arasında pozitif anlamlı bir ilişki vardır. Eşdeğişkenler arasında ise, regresyon analizi göstermiştir ki kadınlara kıyasla erkekler ile fiziksel aktivite sıklığı arasında negatif anlamlı bir ilişki vardır ( $b=-0.256, \mathrm{SE}=0.129,95 \% \mathrm{Cl}=-0.525-0.014)$, yani kadınlar erkeklere göre daha fazla fiziksel aktivite gerçekleştirmektedirler. Fiziksel aktivite süresi yönünden, regresyon analizi sonucunda bakımlı yeşil alanlar ile kişilerin fiziksel aktivite süreleri arasında pozitif anlamlı ilişki bulunmuştur $(b=0.221, \mathrm{SE}=0.058$, 95\% Cl=0.006-0.235). Regresyon analizi başka anlamlı sonuç göstermemiştir.

Çizelge 3.Kentsel yeşil alanların kalitesi ile yetişkinlerin fiziksel aktivite sıklığı ve süresi arasındaki ilişki

\begin{tabular}{|c|c|c|c|c|}
\hline \multirow[t]{2}{*}{ Değişkenler } & \multicolumn{2}{|c|}{$\begin{array}{l}\text { Fiziksel aktivite } \\
\text { sıklığı }\end{array}$} & \multicolumn{2}{|c|}{$\begin{array}{l}\text { Fiziksel aktivite } \\
\text { süresi }\end{array}$} \\
\hline & $\boldsymbol{b}$ & SE & $\boldsymbol{b}$ & SE \\
\hline Cinsiyet (erkek) & $-0.256^{*}$ & 0.129 & -0.193 & 0.112 \\
\hline Yaş & 0.000 & 0.007 & 0.001 & 0.006 \\
\hline Eğitim & 0.079 & 0.075 & 0.025 & 0.065 \\
\hline Bekar & 0.055 & 0.173 & 0.050 & 0.150 \\
\hline İşsiz & 0.082 & 0.160 & 0.040 & 0.139 \\
\hline Emekli & 0.053 & 0.250 & 0.039 & 0.218 \\
\hline Aylık Gelir & 0.035 & 0.054 & 0.056 & 0.047 \\
\hline Yeşil alanlara olan mesafe & $-0.136 * *$ & 0.051 & -0.005 & 0.044 \\
\hline Estetik & -0.047 & 0.080 & -0.024 & 0.070 \\
\hline Temizlik & $0.380^{*}$ & 0.182 & 0.124 & 0.159 \\
\hline Büyüklük & -0.005 & 0.076 & 0.014 & 0.066 \\
\hline Bakımlılık & $0.329 *$ & 0.162 & $0.278^{*}$ & 0.141 \\
\hline Gölgelik & -0.091 & 0.118 & -0.129 & 0.102 \\
\hline Işıklandırma & -0.062 & 0.093 & 0.072 & 0.081 \\
\hline Açık ve görünürlük & -0.026 & 0.105 & 0.108 & 0.091 \\
\hline $\mathrm{R}^{2}$ & $0.092 * * *$ & & $0.078 * *$ & \\
\hline
\end{tabular}


Yeşil alanların kalitesi ve fiziksel aktivite sıklığı ve süresinin insanların stres, ruh sağlığı ve beden sağlığı ile ilişkisi yine doğrusal regresyon analizi ile incelenmiştir. Çizelge 4'de görüldüğü üzere temiz $(b=0.352, \mathrm{SE}=0.166$, $95 \% \mathrm{Cl}=0.027-0.678)$ ve büyük yeşil alanlar $(b=0.183$, $\mathrm{SE}=0.069,95 \% \mathrm{Cl}=0.048-0.319)$ stres seviyesi arasında pozitif anlamlı bir ilişki bulunmuştur. Eşdeğişkenler arasında ise, regresyon analizi göstermiştir ki eğitim seviyesi ile stres arasında pozitif anlamlı bir ilişki vardır ( $b=0.135, \mathrm{SE}=0.067,95 \% \mathrm{Cl}=0.003-0.268)$. Ruh sağlığ açısında baktığımızda ise regresyon analizi sonucunda sadece eşdeğişkenler arasında anlamlı ilişki bulunmuştur. Analiz sonucunda evlilere kıyasla bekar kişiler ile ruh sağlığı arasında $(b=-0.325 \mathrm{SE}=0.141,95 \%$ $\mathrm{Cl}=-0.603-0.048)$ ve çalışanlara göre emekliler ile ruh sağlığı arasında $(b=-0.442, \mathrm{SE}=0.204,95 \% \mathrm{Cl}=-0.844-$ 0.040 ) negatif anlamlı ilişki bulunmuştur. Genel sağlık açısında ise fiziksel aktivite süresi $(b=0.128, \mathrm{SE}=0.048$, $95 \% \mathrm{Cl}=0.035-0.221)$ ve açık ve görünür yeşil alan $(b=0.169, \mathrm{SE}=0.048,95 \% \mathrm{Cl}=0.022-0.315)$ ile kişilerin genel sağlığı arasında pozitif anlamlı bir ilişki bulunmuştur. Eşdeğişkenler yönünden ise, regresyon analiz göstermiştir ki kişilerin eğitim seviyeleri $(b=0.131$, $\mathrm{SE}=0.053,95 \% \mathrm{Cl}=0.027-0.235)$ ve aylık gelirleri ile $(b=0.094, \mathrm{SE}=0.038,95 \% \mathrm{Cl}=0.019-0.169)$ genel sağlıkları arasında pozitif anlamlı ilişki bulunurken, evlilere kıyasla bekar kişiler ile genel sağlık arasında $(b=-0.278$, $\mathrm{SE}=0.122,95 \% \mathrm{Cl}=-0.518-0.038)$ ve çalışanlara göre emekliler ile genel sağlık arasında $(b=-0.446, \mathrm{SE}=0.177$, $95 \% \mathrm{Cl}=-0.793-0.038$ ) negatif anlamlı ilişki bulunmuştur.

\begin{tabular}{|c|c|c|c|c|c|c|}
\hline \multirow[t]{2}{*}{ Değişkenler } & \multicolumn{2}{|l|}{ Stres } & \multicolumn{2}{|c|}{ Ruh Sağlığı } & \multicolumn{2}{|c|}{ Genel Sağlık } \\
\hline & $b$ & SE & $b$ & SE & $b$ & SE \\
\hline Cinsiyet (erkek) & -0.038 & 0.117 & -0.115 & 0.106 & 0.052 & 0.092 \\
\hline Yaş & 0.002 & 0.007 & 0.002 & 0.006 & -0.010 & 0.005 \\
\hline Eğitim & $0.135^{*}$ & 0.067 & 0.098 & 0.061 & $0.131 *$ & 0.053 \\
\hline Bekar & -0.408 & 0.156 & $-0.325^{*}$ & 0.141 & $-0.278^{*}$ & 0.122 \\
\hline İşsiz & -0.231 & 0.145 & -0.202 & 0.131 & -0.125 & 0.113 \\
\hline Emekli & -0.411 & 0.226 & $-0.442 *$ & 0.204 & $-0.446 *$ & 0.177 \\
\hline Aylık Gelir & 0.089 & 0.049 & 0.063 & 0.044 & $0.094^{*}$ & 0.038 \\
\hline Yeşil alanlara olan mesafe & 0.022 & 0.047 & 0.046 & 0.042 & 0.000 & 0.036 \\
\hline Fiziksel aktivite sıklığı & 0.069 & 0.053 & 0.065 & 0.048 & 0.033 & 0.041 \\
\hline Fiziksel aktivite süresi & 0.055 & 0.061 & 0.067 & 0.055 & $0.128 * *$ & 0.048 \\
\hline Estetik & 0.036 & 0.073 & 0.051 & 0.066 & 0.025 & 0.057 \\
\hline Temizlik & $0.352 *$ & 0.166 & -0.177 & 0.150 & 0.027 & 0.130 \\
\hline Büyüklük & $0.183 * *$ & 0.069 & 0.008 & 0.062 & -0.015 & 0.054 \\
\hline Bakımlılık & 0.178 & 0.147 & 0125 & 0.133 & 0.135 & 0.115 \\
\hline Gölgelik & 0.053 & 0.107 & -0.021 & 0.096 & 0.003 & 0.083 \\
\hline Işıklandırma & -0.025 & 0.084 & -0.035 & 0.076 & -0.054 & 0.066 \\
\hline Açık ve görünürlük & 0.064 & 0.095 & 0.128 & 0.086 & $0.169 *$ & 0.074 \\
\hline $\mathrm{R}^{2}$ & $0.133 * * *$ & & $0.102 * *$ & & $0.202 * *$ & \\
\hline
\end{tabular}

${ }^{* * *} \mathrm{p} \leq .001,{ }^{* *} \mathrm{p} \leq .01 ;{ }^{*} \mathrm{p} \leq .05, b$ : Standartlanmamış Katsayılar, SE: Standart Hata

\section{TARTIŞMA}

Bu araştırmanın amacı kentsel yeşil alanların kalitesi ile yetişkinlerin fiziksel aktivite düzeyleri ve stres seviyeleri, ruh ve beden sağlıkları arasındaki ilişkiyi incelemekti. Regresyon analizleri sonucunda yeşil alanların evlere yakınlığı ile insanların fiziksel aktivite sıklığı arasında anlamlı ilişki bulunmuştur ki bu önceki yıllarda yapılan çalışmalarla benzerlik göstermektedir. Yeşil alanların evlere olan mesafesinin fiziksel aktivite sıklığı açısından en önemli faktörlerden bir olduğu önceki yıllarda yapılan araştırmalarda bulunmuştur (Cohen ve ark. 2007; Björk ve ark. 2008; Toftager ve ark. 2011; Akpınar 2014, 2016a ve 2016b). Öyle ki yeşil alanların eve olan mesafesinin 300-400 $\mathrm{m}$ sonrası fiziksel aktivite sıklığının hızlı bir şekilde azaldığı görülmüştür (Grahn ve Stigsdotter 2003; Giles-Corti ve ark. 2005; Nielsen ve Hansen 2007). Yapılan bu çalışmada da önceki yıllarda yapılan araştırmalara paralel olarak yeşil alanların evlere olan mesafesinin artmasıyla insanların fiziksel aktivite seviyeleri azalmaktadır (Şekil 2). Ayrıca, bu çalışmada günlük olarak fiziksel aktivite yapan katılımcıların \%95'i yeşil alanlara 1 km'lik mesafede oturmaktadır. Bu da Avrupa Çevre Ajansının (EEA) insanların yeşil alanlara maksimum 1 km'lik mesafede erişim sağlamaları tavsiyesi ile örtüşmektedir (Stanners ve Bourdeau 1995). 
Sonuç olarak, yeşil alanların evlere olan mesafesi insanların fiziksel aktivite seviyelere üzerinde etkili bir faktör olduğu görülmektedir. Bu sebeple, yeşil alanların planlanması ve tasarımında bu faktör planlamacılar, yerel yöneticiler ve peyzaj mimarları tarafından göz önünde bulundurulmalıdır.

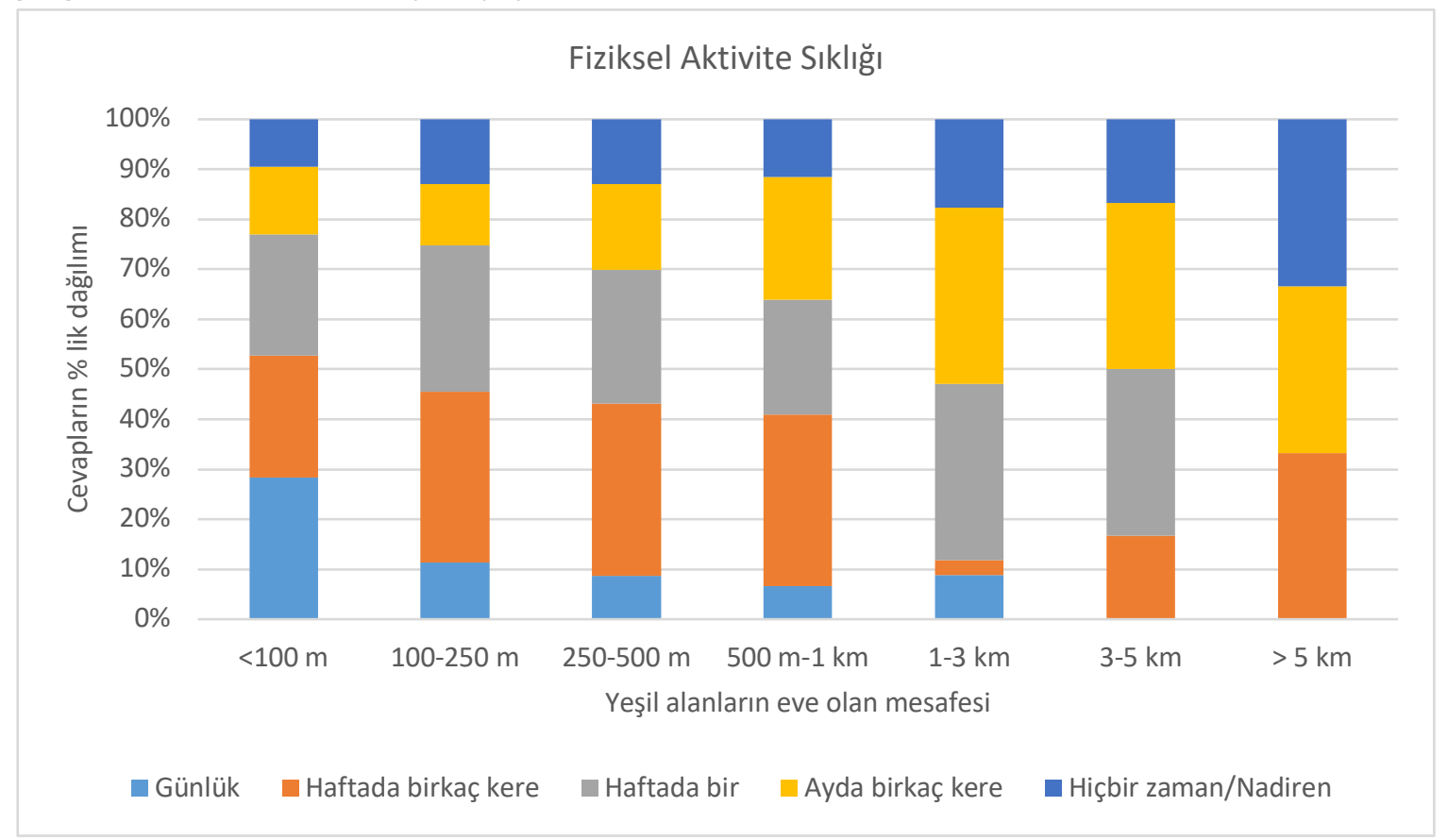

Şekil 2.Kentsel yeşil alanların evlere olan mesafesi ve insanların fiziksel aktivite seviyeleri arasındaki ilişki

Kentsel yeşil alanların kalitesi ve insanların fiziksel aktivite seviyesi arasındaki ilişkiye bakıldığında, temiz yeşil alanlar ile fiziksel aktivite sıklığı arasında anlamlı ilişki bulunurken, bakımlı yeşil alanlar ile fiziksel aktivite sıklığı ve süresi arasında anlamlı iliş̧i bulunmuştur. Önceki yıllarda yapılan çalışmalara bakıldığında yeşil alanların bakımlılığı ve temizliğinin insanların fiziksel aktivite seviyelerini etkileyen önemli bir faktör olduğu görülmektedir (Ferré ve ark. 2006; McCormack ve ark. 2010; Akpınar, 2016a). Örneğin, daha önceki çalışmalarda kentsel yeşil alanlardaki çim alanların bakımlı olması insanlar tarafından bu alanlara özen gösterildiğini ve kentsel yeşil alanların güvenli hissettirdiği şeklinde yorumlanmıştır (LaGrange ve ark. 1992; Brown ve Bentley 1993). Benzer şekilde, ülkemizde yapılan çalışmada da bakımlı ve temiz yeşil alanlar ile insanların fiziksel aktivite sıklığı arasında pozitif ilişki bulunmuştur (Akpınar 2016a). Diğer taraftan ise, eğer ki bir kentsel yeşil alanın, insanların evlerine yakın olmasına rağmen, bakımı yeterince yapılmıyor veya bakımsız bırakılıyorsa, bu durum insanların bu alanı kullanmaları ile ilgili cesaretini kırabilmektedir (Powell ve ark. 2003). Sonuç olarak ta kentsel yeşil alanın kullanımında azalma ya da tamamen kullanımın terkedilmesi gerçekleşebilmektedir (Boone-Heinonen ve ark. 2010). Önceki yıllarda yapılan çalışmalar ve bu araştırmanın sonuçlarını birlikte değerlendirdiğimizde, bakalım ve temiz kentsel yeşil alanların insanların fiziksel aktivite sıklığı ve süresini olumlu etkilediği söylenebilir. Bu sebeple, belediyelerce kentsel yeşil alanların bakımının ve temizliğinin düzenli yapılması önem arz etmektedir.

Kentsel yeşil alanların kalitesi ve sağlık arasındaki ilişki açısından yapılan analiz sonucunda ise temiz ve bakımlı yeşil alanların stres seviyesi ile olumlu ilişkide olduğu; fiziksel aktivite süresi ve açık ve görünür yeşil alanlar ile genel sağlık arasında olumlu ilişki bulunmuştur. Bu buluna sonuçlar önceki çalışmalar göz önünde bulundurulduğunda beklenen bir sonuçtur. Yeşil egzersiz olarak ta adlandırılan yeşil alanlarda yapılan fiziksel aktivitenin kalp hastalıkları riskini azalttı̆̆ı (Sallis ve ark. 2012; Tamosiunas ve ark. 2014) ve öfke-düşmanlık, kafa karışıklığı, depresyon-dejeksiyon, gerginlik-endişe (Pretty ve ark. 2007; Barton ve Pretty 2010) ve stres ve kaygıyı azaltarak (Mackay ve Neill 2010) ve refahı ve benlik saygısını iyileştirerek (Barton ve Pretty 2010) sağlık 
açısından faydaları sağlamaktadır. Ayrıca, önceki yıllarda yapılan çalışmaları inceleyen bir araştırmada da fiziksel aktivitenin sağlıkla ilişkili yaşam kalitesini geliştirdiği belirlenmiştir (Lee ve Maheswaran 2010). Bu durum yeşil alanların insan sağlığı açısından önemini göstermektedir.

Yeşil alanların büyüklüğü ve açık/görünür yeşil alanlar açısından değerlendirdiğimizde ise, yeşil alanların büyüklüğünün insanların fiziksel aktivite seviyesini artıran başlıca önemli bir faktör olduğu önceki yıllarda yapılan araştırmalarda belirlenmiştir (Giles-Corti ve ark. 2005; Kaczynski ve ark. 2008; Sugiyama ve ark. 2010; Paquet ve ark. 2013; Akpınar 2016a). Örneğin Paquet ve ark. (2013) yaptığı çalışmada büyük kentsel yeşil alanların daha yüksek fiziksel aktivite seviyesi ve daha az kalp sorunları ile ilişkisi olduğu bulunmuştur. Öyle görünüyor ki, büyük kentsel yeşil alanlar insanlara daha uzun fiziksel aktivite yapmalarına imkân sağlamaktadır. Ayrıca, Schipperijn ve ark. (2013) yaptığı çalışmada kentsel yeşil alanlardaki açık alanlar kullanıcılar tarafından en önemli özelliklerden bir olarak kabul edilmiştir. $\mathrm{Bu}$ çalışmada da benzer sonuçlar bulunmuştur. Aydın kent merkezindeki parkların çoğunlukla küçük, birbirinden bağımsız dağılmış bir vaziyette ve şehirleşmeden dolayı da etrafı binalarla kapanmasından dolayı açık görünür bir durumda değillerdir. Bu açıdan değerlendirildiğinde, kullanıcıların büyük ve açık/görünür kentsel yeşil alanlar istemesi mantıkı bir sonuçtur. Bu sonuçların belediye yetkilileri, şehir bölge plancıları ve peyzaj mimarları tarafından dikkate alınması önem arz etmektedir.

\section{SONUÇ VE ÖNERILER}

Sonuç olarak, bu çalışma detaylı bir analiz yaparak kentsel yeşil alanların kalitesi ile yetişkinlerin fiziksel aktivite düzeyleri ve stres seviyeleri, ruh ve beden sağlıkları arasındaki ilişki incelenmiştir. Yeşil alanların insan sağlığı ve fiziksel aktivite seviyesi üzerindeki etkisi her geçen yıl daha da bir önem kazanmakta ve bu konuyla ilgili çalışmalar artmaktadır. Ancak, bu konuyla ilgili araştırmalar daha çok gelişmiş ülkelerde yapılmaktadır (Lachowycz ve Jones 2011; Nieuwenhuijsen ve ark. 2014; Bancroft ve ark. 2015; Koohsari ve ark. 2015) ve gelişmekte olan ülkelerinde bu konuya daha fazla katkı sağlamaları gerekmektedir
(Kabisch ve ark. 2015). Bu kapsamda bu çalışmada önemli sonuçlar elde edilmiştir:

- Kentsel yeşil alanların evlere olan mesafesinin fiziksel aktivite açısından önemli faktörlerden biri olduğu,

- Fiziksel aktivite süresi ile genel sağlık arasında anlamlı pozitif ilişki olduğu,

- Kentsel yeşil alanların temizliğinin fiziksel aktivite sıklığı ile, yeşil alanların bakımlılığının ise fiziksel aktivite sıklığı ve süresi ile anlamlı pozitif ilişkili olduğu,

- Büyük ve açık görünür yeşil alanların genel sağlık ile anlamlı pozitif ilişkili olduğu,

- Ve temizlik ve büyüklüğün insanların stres seviyesi ile anlamlı pozitif ilişkili olduğu bulunmuştur.

Yeşil alanların insanların ve çocukların fiziksel aktivite seviyeleri ve sağlıkları üzerindeki etkisini belirlemek önem arz etmektedir. Çünkü, Sağlık Bakanlığı'nın verilerine göre Türkiye'de yetişkin kadınların \%87'si ve yetişkin erkeklerin \%77'si herhangi bir fiziksel aktivitede bulunmaktadır (The Ministry of Health 2014). Öyle ki hareketsiz yaşam tarzının yetişkinler için zararları bilinmektedir (Lee ve ark. 2012; Sallis ve ark. 2012; The Ministry of Health 2014). Diğer taraftan ise fiziksel aktivitenin yetişkinler için faydaları bilinmektedir (Sallis ve ark. 2012; The Ministry of Health 2014; Akpınar 2016a ve 2016b). Buradan hareketle insanların fiziksel aktivite seviyelerinin artırılması elzemdir. Bu kapsamda aşağıdaki maddeler bu çalışmanın sonuçlarına dayandırılarak tavsiye edilmektedir:

- Kentsel yeşil alanlar insanların evlerinin maksimum $1000 \mathrm{~m}$ ya da 15 dakikalık mesafede konumlandırılmalıdır.

- Kentsel yeşil alanlar bakımlı ve temiz olmalıdır. Ayrıca, büyük ve açık görünür yeşil alanlar planlanıp tasarımlar ona göre şekillendirilmelidir.

Bu çalışma göz önünde bulundurularak ileride yapılacak çalışmalar için şu hususlar tavsiye edilmektedir. Öncelikle bu çalışma kişisel bildirim üzerine kurgulanmıştır. Her ne kadar bu metot araştırmacılar tarafından yaygın bir şekilde kullanılsa da insanlar fiziksel aktivite seviyeleri hususunda gerçekte olmayan, abartılı, yanlış ya da eksik bilgiler verebilmektedir. O yüzden ileride yapılacak 
çalışmalarda GPS bazlı ivmeölçer (akselerometre) ile yeşil alanları ziyaret edip etmedikleri ya da hangi sıklıkta ve sürede yeşil alanlarda fiziksel aktivitede bulundukları belirlenmelidir. Bu şekilde daha objektif bir sonuç elde edilebilir. İkinci olarak insanların fiziksel aktivite için daha çok hangi yeşil alanları tercih ettikleri ve bu alanların özelliklerinin ne olduğu belirlenmelidir. Bir yeşil alanın evlere olan mesafesi yakın dahi olsa bu yeşil alan insanların isteklerine hitap etmiyorsa ya da bu yeşil alan aktif yeşil alan değilse yeşil alanın eve olan mesafesi ile ilgili sonuç yanlış çıkabilir. Bu yüzden insanların nerelere fiziksel aktivite için gittiklerinin belirlenmesi gerekmektedir. Üçüncü olarak, yeşil alanların insanların evlerine mesafesi GPS kullanılarak koordinasyonuyla birlikte belirlenmelidir. Diğer bir husus ise, yeșil alanların evlere mesafesi hesaplanırken yol ve kaldırım sirkülasyonu hesaplanmalıdır. Direk evlerden yeşil alana çizilecek doğru bir çizgiyle yapılacak araştırma hata oranını artırabilmektedir.

\section{TEŞEKKÜR}

ZRF-16006 numaralı bu çalışma Adnan Menderes Üniversitesi Bilimsel Araştırma Projeleri Birimi tarafından desteklenmiştir.

\section{REFERENCES}

Akpınar A (2014) Kullanıcıların kentsel yeşil yolları kullanım sebepleri, algıları ve tercihlerinin Aydın-Koşuyolu örneğinde incelenmesi (Assessing the users ' perceptions, preferences, and reasons for use of urban greenway in Aydın-Koşuyolu province). Journal of the Faculty of Forestry Istanbul University, 64(2): 41-55. doi:10.17099/jffiu.31281

Akpınar A (2016a) How is quality of urban green spaces associated with physical activity and health? Urban Forestry \& Urban Greening, 16: 76-83.

Akpınar A (2016b) Factors influencing the use of urban greenways: A case study of Aydın, Turkey. Urban Forestry \& Urban Greening, 16: 123-131.

Akpınar A, Cankurt M (2017) How are characteristics of urban green space related to levels of physical activity: Examining the links. Indoor and Built Environment, 26(8): 1091-1101.

Amorim TC, Azevedo MR, Hallal PC (2010) Physical activity levels according to physical and social environmental factors in a sample of adults livingin South Brazil. Journal of Physical Activity and Health, 7(Suppl 2): S204-S212.

Ball K, Bauman A, Leslie E, Owen N (2001) Perceived Environmental Aesthetics and Convenience and Company Are Associated with Walking for Exercise among Australian Adults. Preventive Medicine, 33: 434-440.

Bancroft C, Joshi S, Rundle A, Hutson M, Chong C, Weiss CC (2015) Association of proximity and density of parks and objectively measured physical activity in the United States: A systematic review. Social Science \& Medicine. 138: 22-30, doi: 10.1016/j.socscimed.2015.05.034

Barton J, Pretty J (2010) What is the best dose of nature and green exercise for improving mental health? A multi-study analysis. Environmental Science \& Technology, 44: 3947-3955.

Bedimo-Rung AL, Mowen A, Cohen D (2005) The Significance of Parks to Physical Activity and Public Health: A Conceptual Model. American Journal of Preventive Medicine, 28(2S2): 159-168.

Björk J, Albin M, Grahn P, Jacobsson H, Ardö J, Wadbro J, Östergren PO, Skärbäck E (2008) Recreational values of the natural environment in relation to neighbourhood satisfaction, physical activity, obesity and wellbeing. Journal of Epidemiology and Community Health, 62(e2).

Boone-Heinonen J, Casanova K, Richardson A, Gordon-Larsen P (2010) Where can they play? Outdoor spaces and physical activity among adolescents in U.S. urbanized areas. Prev Med., 51(3-4): 295-298.

Bowler DE, Buyung-Ali LM, Knight TM, Pullin AS (2010) A systematic review of evidence for the added benefits to health of exposure to natural environments. BMC Public Health, 10(456).

Brown B, Bentley DL (1993) Residential burglars judge risk: the role of territoriality. J Environ Psychol, 13: 51- 61.

Cohen DA, Ashwood JS, Scott MM, Overton A, Evenson KR, Staten LK, Porter D, Mckenzie TL, Catellier D (2006) Public parks and physical activity among adolescent girls. Pediatrics, 118, e1381e1389.

Cohen D, McKenzie T, Sehgal A, Williamson S, Golinelli D, Lurie N (2007) Contribution of public parks to physical activity. American Journal of Public Health, 97: 509-514.

Dadvand $P$, Bartoll X, Basagaña X, Dalmau-Bueno A, Martinez D, Ambros A, Cirach M, Triguero-Mas M, Gascon M, Borrell C, Nieuwenhuijsen M (2016) Green spaces and General Health: Roles of mental health status, social support, and physical activity. Environment International, 91: 161-167.

de Jong K, Albin M, Skarback E, Grahn P, Wadbro J, Merlo J, Bjork J (2011) Area-aggregated assessments of perceived environmental attributes may overcome single-source bias in studies of green environments and health: Results from a cross-sectional survey in southern Sweden. Environmental Health, 10(4).

de Vries S, van Dillen SM, Groenewegen PP, Spreeuwenberg P (2013) Streetscape greenery and health: Stress, social cohesion and physical activity as mediators. Social Science \& Medicine, 94: 2633.

Duncan M, Mummery K (2005) Psychosocial and environmental factors associated with physical activity among city dwellers in regional Queensland. Preventive Medicine, 40: 363-372.

Evenson KR, Birnbaum AS, Bedimo-Rung AL, Sallis JF, Voorhees CC, Ring K, Elder JP (2006) Girls' perception of physical environmental factors and transportation: Reliability and association with physical activity and active transport to school. International Journal of Behavioral Nutrition and Physical Activity, 3(28).

Ferré MB, Guitart AO, Ferret MP (2006) Children and playgrounds in Mediterranean cities. Children's Geographies, 4(2): 173-183.

Foster C, Hillsdon M, Thorogood M (2004) Environmental perceptions and walking in English adults. Journal of Epidemiology \& Community Health, 58: 924-928.

Francis J, Wood L, Knuiman M, Giles-Corti B (2012) Quality or quantity? Exploring the relationship between Public Open Space attributes and mental health in Perth, Western Australia. Social Science \& Medicine, 74: 1570-1577.

Giles-Corti B, Broomhall M, Knuiman M, Collins C, Douglas KN, Lange A, Donovan R (2005) Increasing walking. How important is 
distance to, attractiveness, and size of public open space? American Journal of Preventive Medicine, 28(2S2): 169-176.

Grahn P, Stigsdotter UA (2003) Landscape planning and stress. Urban Forestry \& Urban Green, 2: 1-18.

Hallal PC, Andersen L, Bull F, Guthold R, Haskell W, Ekelund U (2012) Global physical activity levels: surveillance progress, pitfalls, and prospects. Lancet, 380: 247-57.

Hartig T, Mitchell R, de Vries S, Frumkin H (2014) Nature and Health. Annu. Rev. Public Health, 35: 207-28.

Hillsdon M, Panter J, Foster C, Jones A (2006) The relationship between access and quality of urban green space with population physical activity. Public Health, 120(12): 1127-32.

İmar ve Şehircilik Dairesi Başkanlığı (2013) Aydın Büyükşehir Belediyesi Nazım İmar Planı. Aydın Büyükşehir Belediyesi.

Jones A, Hillsdon M, Coombes E (2009) Greenspace access, use, and physical activity: Understanding the effects of area deprivation. Preventive Medicine, 49: 500-505.

Kabisch N, Qureshi S, Haase D (2015) Human-environment interactions in urban green spaces - A systematic review of contemporary issues and prospects for future research. Environmental Impact Assessment Review, 50: 25-34.

Kaczynski AT, Henderson KA (2007) Environmental correlates of physical activity: A review of evidence about parks and recreation. Leisure Science: An Interdisciplinary Journal, 29(4): 315-354.

Kaczynski AT, Potwarka LR, Saelens BE (2008) Association of park size, distance and features with physical activity in neighborhood parks. American Journal of Public Health, 98: 1451-1456.

Kaczynski AT, Potwarka LR, Smale BJ, Havitz ME (2009) Association of Parkland Proximity with Neighborhood and Park-based Physical Activity: Variations by Gender and Age. Leisure Sciences: An Interdisciplinary Journal, 31(2): 174-191.

Koohsari MJ. Mavoa S, Villanueva K, Sugiyama T, Badland $H$, Kaczynski A, Owen N, Giles-Corti B (2015) Public open space, physical activity, urban design and public health: Concepts, methods and research agenda. Health \& Place, 33: 75-82.

Lachowycz K, Jones AP (2011) Greenspace and obesity: a systematic review of the evidence. obesity reviews, 12: e183-e189.

LaGrange R, Ferraro K, Supancic M (1992) Perceived risk and fear of crime: role of social and physical incivilities. J Res Crime Delinquency, 29: 311-34.

Lee AC, Maheswaran R (2010) The health benefits of urban green spaces: a review of the evidence. Journal of Public Health, 1-11.

Lee I-M, Shiroma E, Lobelo F, Puska P, Blair S, Katzmarzyk P (2012) Effect of physical inactivity on major non-communicable diseases worldwide: an analysis of burden of disease and life expectancy. Lancet, 380(9838): 219-229.

Maas J, Verheij R, Spreeuwenberg P, Groenewegen P (2008) Physical activity as a possible mechanism behind the relationship between green space and health: A multilevel analysis. BMC Public Health, 8: 206-218.

Mackay GJ, Neill JT (2010) The effect of "green exercise" on state anxiety and the role of exercise duration, intensity, and greenness: A quasi-experimental study. Psychology of Sport and Exercise, 11: 238-245.

McCormack GR, Rock M, Toohey AM, Hignell D (2010) Characteristics of urban parks associated with park use and physical activity: A review of qualitative research. Health \& Place, 16: 712-726.

Mowen A, Orsega-Smith E, Payne L, Ainsworth B, Godbey G (2007) The role of park proximity and social support in shaping park visitation, physical activity, and perceived health among older adults. Journal of Physical Activity and Health, 4: 167-179.
Nielsen TS, Hansen KB (2007) Do green areas affect health? Results from a Danish survey on the use of green areas and health indicators. Health \& Place, 13: 839-850.

Nieuwenhuijsen MJ, Kruize $\mathrm{H}$, Gidlow C, Andrusaityte S, Antó J, Basagaña $X$, Cirach $M$, Dadvand $P$, Danileviciute $A$, DonaireGonzalez D, Garcia J, Jerrett M, Jones M, Julvez J, van Kempen E, van Kamp I, Maas J, Seto E, Smith G, Triguero M, Wendel-Vos W, Wright J, Zufferey J, van den Hazel PJ, Lawrence R, Grazuleviciene $R$ (2014) Positive health effects of the natural outdoor environment in typical populations in different regions in Europe (PHENOTYPE): a study programme protocol. BMJ Open, 4.

Paquet C, Orschulok TP, Coffee N, Howard NJ, Hugo G, Taylor AW, Adams RJ, Daniel M (2013) Are accessibility and characteristics of public open spaces associated with a better cardiometabolic health? Landscape and Urban Planning, 118: 70-78.

Peschardt KK, Stigsdotter U (2013) Associations between park characteristics and perceived restorativeness of small public urban green spaces. Landscape \& Urban Planning. 112: 26-39.

Powell KE, Martin LM, Chowdhury PP (2003) Places to Walk: Convenience and Regular Physical Activity. American Journal of Public Health, 93: 1519-1521.

Pretty J, Peacock J, Hine R, Sellens M, South N, Griffin M (2007) Green Exercise in the UK Countryside: Effects on Health and Psychological Well-Being, Implications for Policy and Planning. Journal of Environmental Planning and Management, 50(2): 211231.

Sağlık Bakanlığı (2014) Türkiye Beslenme ve Sağlık Araştırması 2010: Beslenme Durumu ve Alışkanlıklarının Değerlendirilmesi Sonuç Raporu (Turkey Nutrition and Health Survey 2010: Status and Assessment of Nutritional Habits Final Report). Ankara: Sağlık Bakanlığı Sağlık Araştırmaları Genel Müdürlüğü, Hacettepe Üniversitesi Sağlık Bilimleri Fakültesi Beslenme ve Diyetetik Bölümü, Ankara Numune Eğitim ve Araştırma Hastanesi.

Sallis JF, Floyd MF, Rodríguez DA, Saelens BE (2012) The Role of Built Environments in Physical Activity, Obesity, and CVD. Circulation, 125(5): 729-737.

Sallis JF, Owen N, Fisher EB (2008) Ecological models of health behavior. In K Glanz, BK Rimer, K. Vismanath, Health behavior and health education: Theory, research, and practice (pp. 565485). San Francisco: Jossey-Bass.

Schipperijn J, Bentsen P, Troelsen J, Toftager M, Stigsdotter U (2013) Associations between physical activity and characteristics of urban green space. Urban Forestry \& Urban Greening, 12: 109116.

Schipperijn J, Ekholm O, Stigsdotter UK, Toftager M, Bentsen P, Kamper-Jørgensen F, Randrup TB (2010). Factors influencing the use of green space: Results from a Danish national representative survey. Landscape and Urban Planning, 95: 130-137.

Smith S (2013) Determining Sample Size: How to Ensure You Get the Correct Sample Size. Erişim 10 Nisan 2014, http://www.qualtrics.com/blog/determining-sample-size/

Stanners D, Bourdeau P (1995) The urban environment. In D Stanners, P Bourdeau, Europe's Environment: The Dobris Assessment (pp. 261-296). Copenhagen: European Environment Agency.

Sugiyama T, Francis J, Middleton NJ, Owen N, Giles-Corti B (2010) Associations between recreational walking and attractiveness, size, and proximity of neighborhood open spaces. American Journal of Public Health, 100(9): 1752-7.

Sugiyama T, Leslie E, Giles-Corti B, Owen N (2008) Associations of neighbourhood greenness with physical and mental health: Do walking,social coherence and local social interaction explain the relationships? Journal of Epidemiol Community Health, 62(5): 1-6. 
Tamosiunas A, Grazuleviciene R, Luksiene D, Dedele A, Reklaitiene R, Baceviciene M, Vencloviene J, Bernotiene G, Radisauskas R, Malinauskiene V, Milinaviciene E, Bobak M, Peasey A, Nieuwenhuijsen M (2014) Accessibility and use of urban green spaces, and cardiovascular health: findings from a Kaunas cohort study. Environmental Health, 13(20).

Taylor LM, Leslie E, Plotnikoff R, Owen N, Spence J (2008) Associations of Perceived Community Environmental Attributes with Walking in a Population-Based Sample of Adults with Type 2 Diabetes. Ann. Behav. Med, 35: 170-178.

The Ministry of Health (2014) Physical Activity Guidelines for Turkey. Ankara: The Ministry of Health of Turkey, Public Health
Institution, Department of Obesity, Diabetes and Metabolic Diseases.

Toftager M, Ekholm O, Schipperijn J, Stigsdotter UK, Bentsen P, Grønbæk M, Randrup TB, Kamper-Jørgensen F (2011) Distance to green space and physical activity: a Danish national representative survey. Journal of Physical Activity and Health, 8, 741-749.

WHO (2019) Global Strategy on Diet, Physical Activity and Health. Geneva. Erişim 4 Şubat 2019, https://www.who.int/dietphysicalactivity/pa/en/. 